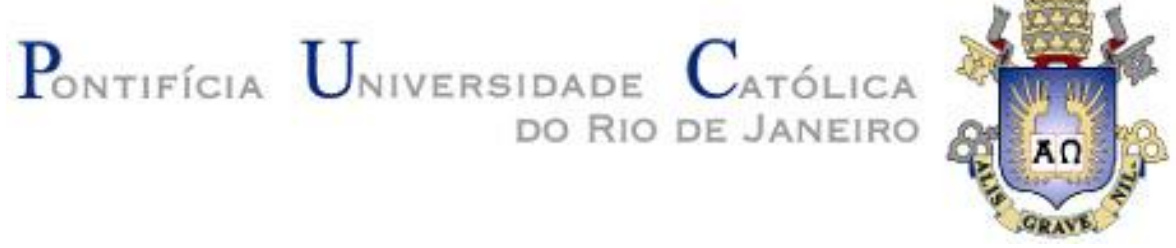

André Carvalho Foster Vidal

Relação entre Governança Corporativa e Remuneração de Executivos no Brasil

Dissertação de Mestrado

Dissertação apresentada como requisito parcial para obtenção do título de Mestre pelo Programa de PósGraduação em Administração de Empresas da PUCRio.

Orientador: Prof. Andre Luiz Carvalhal da Silva 


\title{
Relação entre Governança Corporativa e Remuneração de Executivos no Brasil
}

\begin{abstract}
Dissertação apresentada como requisito parcial para obtenção do título de Mestre pelo Programa de PósGraduação em Administração de Empresas da PUC-Rio. Aprovada pela Comissão Examinadora abaixo assinada.
\end{abstract}

Prof. André Luiz Carvalhal da Silva Orientador Departamento de Administração - PUC-Rio

Prof. Luiz Felipe Jacques da Motta Departamento de Administração - PUC-Rio

Prof. Ricardo Pereira Câmara Leal Instituto Coppead de Administração - UFRJ

Monica Herz

Vice-Decana de Pós-Graduação do CCS 
Todos os direitos reservados. É proibida a reprodução total ou parcial do trabalho sem autorização da universidade, do autor e do orientador.

\section{André Carvalho Foster Vidal}

Graduado em Administração pela Universidade Federal do Rio de Janeiro (UFRJ) em 2007. Trabalhou como analista financeiro na Casa \& Video de 2007 a 2009. Desde 2009, realiza analises setoriais no departamento de papel e celulose do Banco Nacional de Desenvolvimento Econômico e Social (BNDES).

Ficha Catalográfica

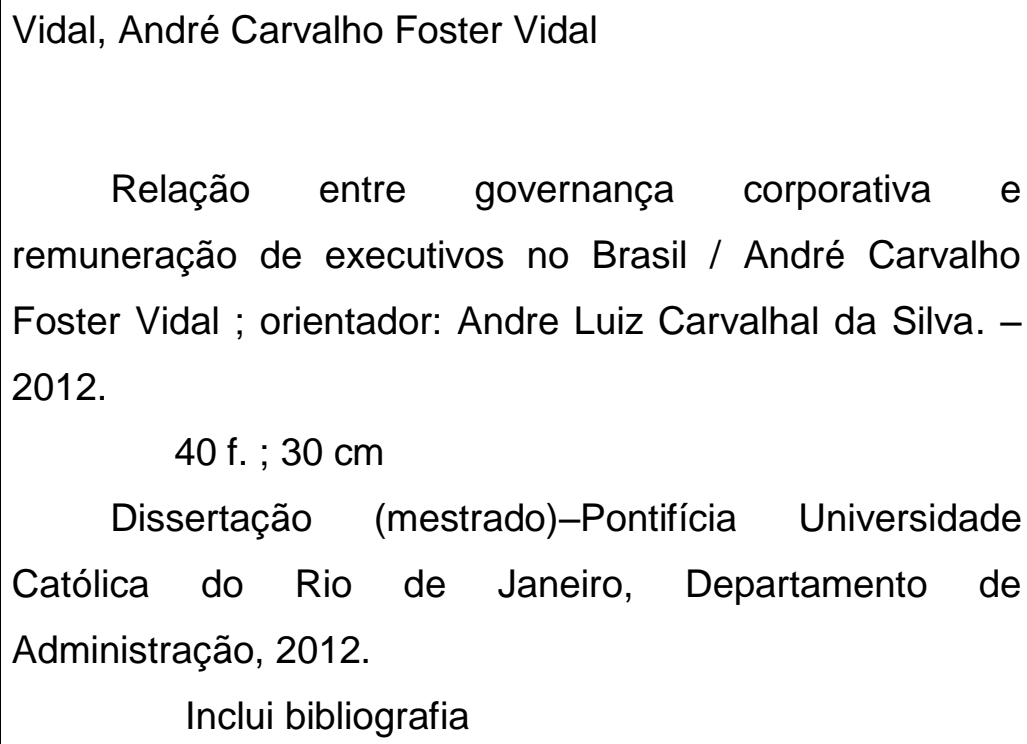

1. Administração - Teses. 2. Governança corporativa. 3. Remuneração de executivos. 4. Mercados emergentes. I. Silva, Andre Luiz Carvalhal da. II. Pontifícia Universidade Católica do Rio de Janeiro. Departamento de Administração. III. Título. 
Aos meus pais, Maria Luisa, Ronaldo, Marcelo e Eleonore, pelo apoio e amor ao longo de toda a minha vida 


\section{Agradecimentos}

Ao meu orientador, pelo apoio ao longo da realização deste trabalho.

Aos colegas da PUC, pela ajuda e companheirismo.

Aos meus pais, pelo carinho e incentivo.

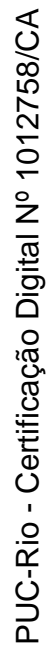

A minha namorada, Anna Carolina, pelo amor e compreensão em todos os finais de semana de estudo ao longo do mestrado. 


\section{Resumo}

Vidal, André Carvalho Foster; Silva, André Luiz Carvalhal da. Relação entre Governança Corporativa e Remuneração de Executivos no Brasil. Rio de Janeiro, 2012. 40p. Dissertação de Mestrado - Departamento de Administração, Pontifícia Universidade Católica do Rio de Janeiro.

Este estudo tem como objetivo analisar a relação entre remuneração de administradores e a adoção de boas práticas de governança corporativa nas empresas brasileiras de capital aberto. Este não é um tema novo e, particularmente nos últimos anos, tem crescido a quantidade de pesquisas abordando este assunto no Brasil. Porém, o número de trabalhos no país ainda é reduzido, em função da menor disponibilidade de informações e do menor tamanho do nosso mercado em comparação ao norte-americano. Esse estudo traz uma grande contribuição ao tema, por ser o primeiro a considerar a mais ampla base de dados (em relação ao número de empresas e ao período) pública disponível sobre remuneração de executivos em empresas brasileiras de capital aberto. Os resultados indicam que, controlando por diversas características da firma e considerando a governança corporativa de uma maneira agregada, empresas com boas práticas de governança corporativa tendem a pagar remunerações mais elevadas a seus executivos, o que pode parecer contraditório, em vista a literatura internacional e nacional sobre o tema. Entretanto, ao considerar a governança corporativa de forma mais ampla, foi encontrado que as dimensões de transparência e estrutura de controle possuem relação positiva com remuneração de executivos, ao passo que as dimensões conselho de administração e direitos dos acionistas possuem uma relação negativa.

\section{Palavras-chave}

Governança corporativa; Remuneração de executivos; Mercados emergentes. 


\section{Abstract}

Vidal, André Carvalho Foster; Silva, André Luiz Carvalhal da (Advisor). Relation Between Executive Remuneration and Corporate Governance in Brazil. Rio de Janeiro, 2012. 40p. MSc. Dissertation - Departamento de Administração, Pontifícia Universidade Católica do Rio de Janeiro.

This study analyses the relation between executive remuneration and corporate governance in Brazilian listed firms. This topic is not new and the number of papers on this subject has been increasing over time. However, the literature on executive remuneration is not vast in Brazil when compared to the international market, because data is not easily available. This work contributes to the literature by building and analyzing the largest dataset (regarding the number of companies and years) on executive remuneration of Brazilian listed companies. Our results indicate that, after controlling for firm characteristics and considering corporate governance as an aggregate variable, companies with better governance pay a higher remuneration to their executives, both in absolute and relative terms. This result seems contrary to the international literature. However, when governance is analyzed more broadly, we find that disclosure and ownership structure are positively related with executive remuneration, while board practices and shareholder rights have a negative relation with remuneration.

\section{Keywords}

Corporate governance; Executive remuneration; Emerging markets. 


\section{Sumário}

1 Introdução 9

2 Revisão de Literatura $\quad 13$

3 Dados e Metodologia 21

3.1. Dados 21

3.2. Metodologia 22

4 Resultados $\quad 24$

4.1. Estatísticas básicas $\quad 24$

4.2. Relação entre Remuneração Executiva e Governança Corporativa 30

5 Conclusões $\quad 36$

6 Referências Bibliográficas $\quad 38$ 